\title{
An Empirical Study into Social Success Factors for Agile Software Development
}

\author{
E.C.A. van Kelle \\ Software Improvement Group*, Tilburg University ${ }^{\S}$ \\ Amsterdam*, Tilburg ${ }^{\S}$, The Netherlands \\ e.vankelle@sig.eu \\ A. Plaat \\ Leiden Institute of Advanced Computer Science \\ Leiden University \\ Leiden, The Netherlands \\ a.plaat@liacs.leidenuniv.nl
}

\author{
J. Visser \\ Software Improvement Group*, Radboud University ${ }^{\S}$ \\ Amsterdam*, Nijmegen ${ }^{\S}$, The Netherlands \\ j.visser@sig.eu \\ P. van der Wijst \\ Dept. Of Communication and Information Sciences \\ Tilburg University \\ Tilburg, The Netherlands \\ per.vanderwijst@tilburguniversity.edu
}

\begin{abstract}
Though many warn that Agile at larger scale is problematic or at least more challenging than in smaller projects, Agile software development seems to become the norm, also for large and complex projects.

Based on literature and qualitative interviews, we constructed a conceptual model of social factors that may be of influence on the success of software development projects in general, and of Agile projects in particular. We also included project size as a candidate success factor.

We tested the model on a set of 40 projects from 19 Dutch organizations, comprising a total of 141 project members, Scrum Masters and product owners.

We found that project size does not determine Agile project success. Rather, value congruence, degree of adoption of Agile practices, and transformational leadership proved to be the most important predictors for Agile project success.
\end{abstract}

Index Terms - Agile, social success factors, value congruence, transformational leadership.

\section{Introduction}

Agile Software Development methods are originally applied by, and considered successful for, small teams and projects, and scaling up these methods is challenging [1]-[4]. However, larger organizations are also facing the same challenges that Agile methodologies address [1]. Since Agile methods strongly focus on people and interactions, it seems likely that communication- and leadership style are important candidate success factors in Agile project success. In addition, most projects do not fail due to technology, but due to social and organizational problems, a lack of (effective) communication [5] and unaligned teams [6]. Therefore, it is important to gain understanding about which social factors are of significant influence on Agile project success. Specifically, we are also interested in project success at larger scale, since larger IT projects seem to fail more often than smaller projects [7]. Three of the most important challenges when scaling up Agile methods are communication barriers, changing leadership requirements, and ineffective, unaligned teams [e.g. $3,5,6]$. This suggests that social factors could be of significant importance in successfully applying Agile methods, in both small and larger projects.

In this study, we assess the role of communication- and leadership-related factors in Agile project success. Furthermore, we examine whether these candidate success factors are of greater influence in larger, more complex projects. We propose a conceptual model based on qualitative interviews held with best practices and literature. Subsequently, this model is tested quantitatively, in order to determine the relative importance of each candidate success factor in Agile project success.

\section{Goals and Relevance}

The aim of our study was (1) to independently verify earlier identified success factors in Agile Software Development; and (2) to develop and validate a new, more comprehensive conceptual model by examining relationships between various candidate success factors and Agile project success. In terms of theoretical relevance, this study will contribute to the existing literature on leadership and communication, by providing insights into which leadership- and communication style are most suitable in complex, changing environments, such as Agile Software Development. Furthermore, the study can reduce existing research gaps on (social) success factors in (Agile) software development. In addition, the outcome of the study may provide practitioners with guidance on how to improve leadership and/or communication practices. 


\section{Theoretical Background}

Our selection of candidate success factors was based on prior research, which identified several 'people success factors' in Agile Software Development. In our study, candidate success factors include leadership style, communication style, value congruence, degree of adoption of Agile practices and project size. Project success was approached in terms of effectiveness - 'the degree to which a team meets the expectations of the quality of the outcome' [8]- by assessing multiple ratings of success.

Changing leadership requirements are a challenge in successfully applying Agile methods (in larger projects) [e.g. 3]. Leadership style was assessed in terms of transformational and transactional leadership [9]. Transformational leadership refers to an adaptive leadership style that revolves around motivating, inspiring, expressing visions and engaging the emotional involvement of followers, while focusing on longterm commitment and engagement. Transactional leadership refers to social transactions in which expectations and rewards are clearly stated, and a short-term focus exists. We expected that transformational leadership is more suitable in Agile projects than transactional leadership, considering the emphasis on people and interactions in Agile Software Development.

A lack of effective communication and the existence of misunderstanding are main reasons for project failure [e.g. 5]. Specifically informal communication helps building trust, enables the creation of shared values, and stimulates the formation of strong interpersonal relationships [10]-[12], which are considered crucial success factors in Agile Software Development [e.g. 11]. In addition, informal communication allows for quick reaction to problems and changing requirements, which is particularly important in turbulent, changing environments, such as Agile projects. Therefore, we argue that communication style is more important than communication frequency, and that informal communication can enhance Agile project success in both small and larger projects.

Similarity in values and goals is needed to be efficient and effective, and to enhance interpersonal relationships [11]-[13]. When members of a group differ in terms of what they think goals, targets and missions should be, value diversity occurs, which can increase relationship conflict, decrease satisfaction and therefore negatively affect (software) team performance [13]-[14]. Hence, we argue that value congruence may be crucial for aligned teams and Agile project success.

Degree of adoption of Agile practices refers to perceived agility among project members. This variable was included in order to indicate how Agile participating projects were considered to be. Project size refers to the total number of project members per Agile project.

\section{Methods}

The study was conducted in two phases: (1) an explorative phase in which a new, more comprehensive conceptual model was developed; and (2) a validation phase, in which the conceptual model was validated quantitatively.

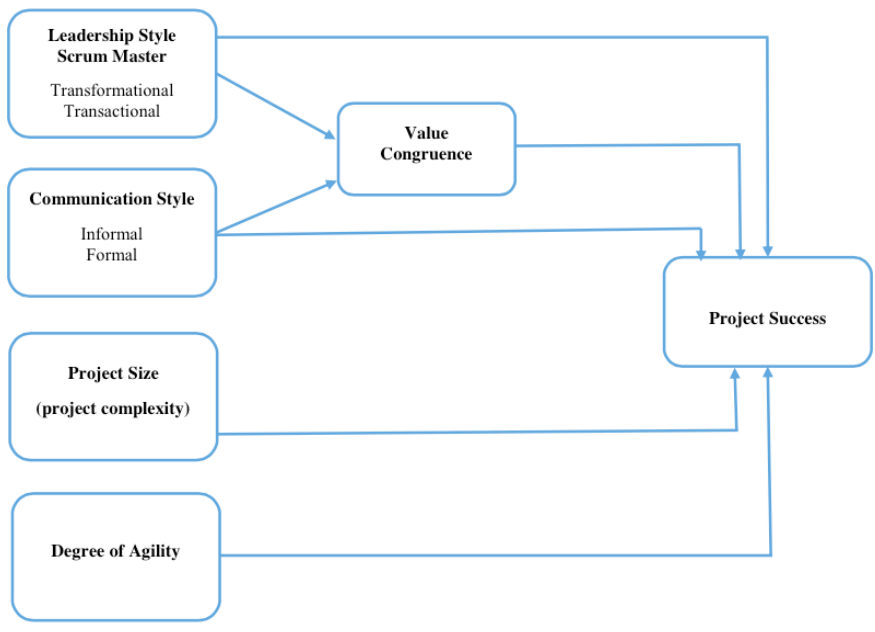

Fig. 1: Conceptual model

In the first, explorative phase, qualitative interviews were conducted with practitioners involved in successful (large) Agile development projects. Topics that were discussed included general information about projects, Agile and leadership, and Agile and communication. The outcomes of these interviews, along with prior research findings, led to the development of a conceptual model. The model includes five candidate success factors: (1) transformational leadership; (2) communication style; (3) value congruence; (4) degree of agility and (5) project size (Figure 1). We expected that the social factors would have a positive effect on project success, whereas project size was expected to negatively affect project success. Furthermore, we expected leadership style and communication style to be mediated by value congruence. The expected relationships between the various factors are depicted as arrows in the figure.

The aim of the second phase was to validate (test) the conceptual model, and thereby determine the relative importance of each candidate success factor. Hypotheses regarding relationships between candidate success factors were tested using data from 141 team members, Scrum Masters and product owners from 40 projects, from 19 Dutch organizations. From all participating projects, at least one team member, Scrum Master and product owner filled out a questionnaire, allowing for comparison of roles and projects. An online questionnaire with 5-point Likert scale questions and demographic information collection was distributed to all respondents. The questionnaire included five sections: (1) demographic information; (2) degree of agility; (3) leadership style, using the Multifactor Leadership Questionnaire (MLQ) [9]; communication style; (4) value congruence; and (5) project success, using a 5-point Likert scale to reflect the level of perception of success. All scales had an acceptable reliability (Cronbach's alpha), except for transactional leadership, which we removed from the dataset.

Regression and mediation analyses were conducted on both individual and project level in order to examine the relative contributions of each candidate success factors to project success. On individual level, respondents were considered one unit of analysis, allowing for different roles to be compared. On 
project level, one project in which roles were clustered was considered one unit of analysis, allowing for projects to be compared. Meditational analyses were conducted when significant relations existed between predictors and the outcome variable.

\section{Results}

Since the data allowed for comparison of roles and projects, we first examined whether team members, Scrum Masters and product owners interpreted project success equally. T-tests showed that there were no significant differences in ratings for project success between different roles. Hence, project success was interpreted in a non-differentiated manner in this study.

Prior to testing the conceptual model, regression analyses were conducted in order to examine relationships between proposed candidate success factors and project success. Analysis showed that significant positive correlations existed between all candidate success factors and project success, except for project size, meaning that no significant correlation was found between project size and project success. Second, results of regression analysis showed that significant predictive relationships existed between (1) transformational leadership and project success; (2) value congruence and project success; and (3) degree of agility and project success. Thus, based on regression analyses, transformational leadership, value congruence, and degree of agility were the most important predictors for project success in this model.

Based on the results of regression analysis, mediation analyses [14] were conducted when predictors were significantly related to both the proposed mediator (value congruence) and project success. Results of mediation analysis showed that value congruence was a mediating factor between candidate success factors and project success in this model. Specifically, full mediation existed between transformational leadership and project success, and partial mediation existed between degree of agility and project success. These results stress the importance of high value congruence among project members, considering that value congruence is both a predictor and mediating factor in relation to project success.

Project size was not found to influence project success, suggesting Agile methodologies could be applied successfully on larger scale as long as there is high value congruence, high degree of agility and transformational leadership.

Results of these statistical analyses allowed for refinement of our original conceptual model (Figure 2). Our findings show that not communication style, but degree of agility is a predictor for Agile project success, and is mediated by value congruence. Significant relationships are depicted as bold arrows in the figure.

\section{Practical Implications}

This study suggests that there are three critical success factors for Agile project success: transformational leadership, value congruence and degree of agility. To assess, to what extent the identified success factors influence project success, we divided participating projects into one group that scored mediocre on candidate success factors, and one group that

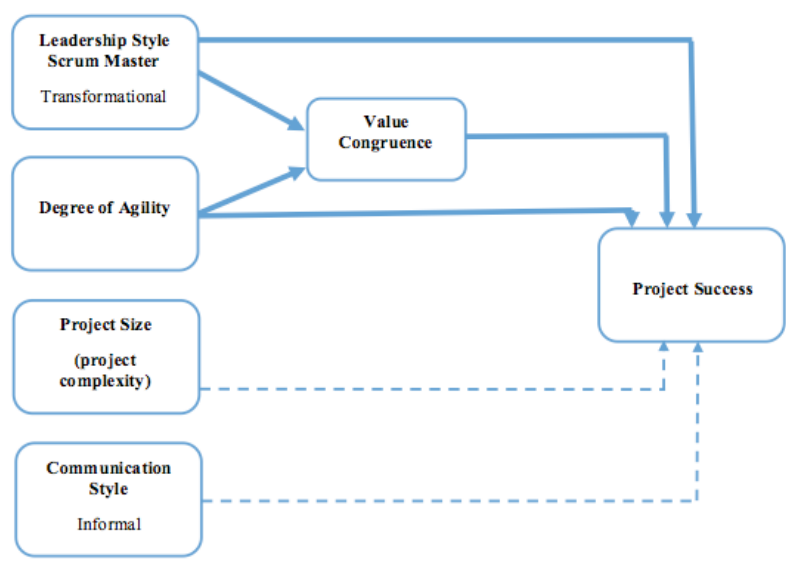

Fig. 2: Revised conceptual model

scored high on candidate success factors. Degree of agility and value congruence showed a larger effect on project success $(0,50$ and 0,45 Likert points, respectively) than transformational leadership $(0,07)$ (Figure 3 ).

To assess the extent to which the three identified success factors reinforce each other or act independently, we inspected the scores on project success for the groups of projects where none, only 1 out of three, 2 out of three or all 3 factors scored high (Figure 4). This revealed monotonously increasing scores for project success, suggesting that all three factors should be given attention to maximize project success.

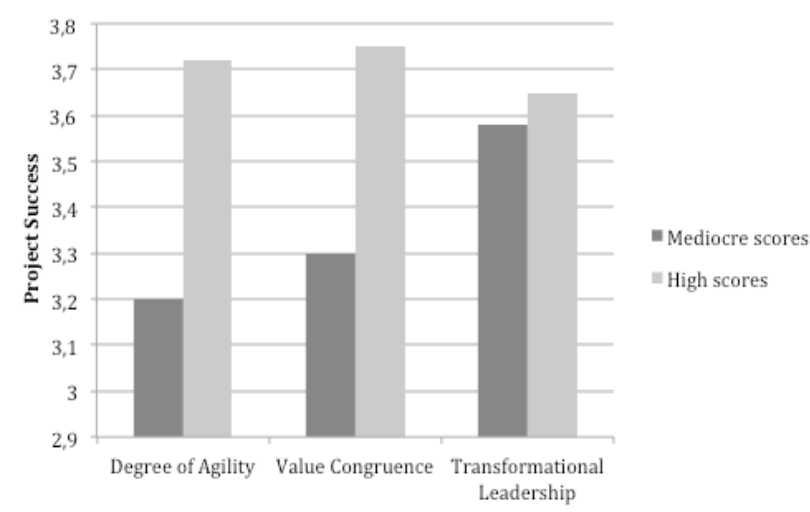

Fig. 3: Critical Success Factors

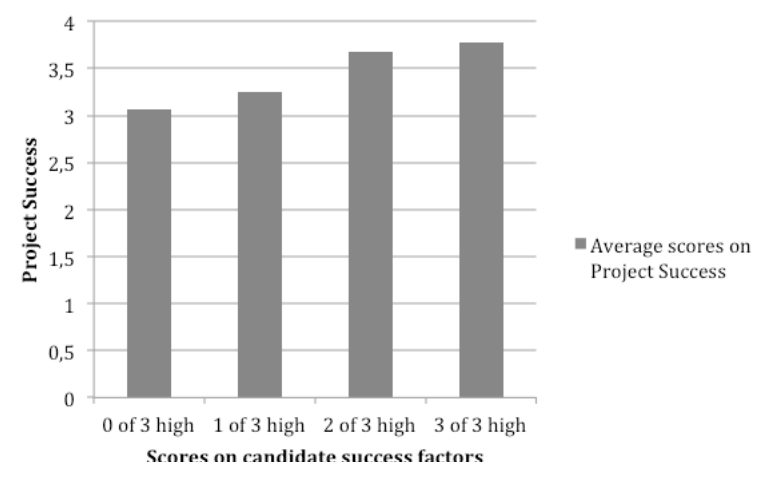

Fig. 4: $\quad$ The Trinity of Agile Project Success 
These findings imply that in Agile projects, there should be a strong focus on the alignment of values regarding the project (goals, priorities, vision). Regular informal communication, and maintaining a transformational leadership style can establish this alignment of values [10]-[12].

\section{Discussion}

This study addressed the question which social factors may determine success of Agile projects, and examined the role of project size. Our study contributes to the empirical identification of (new) communication-related success factors in Agile Software Development, by providing insights into which social factors contribute to Agile project success. We also found that project size does not play a direct role. This implies that the focus of managers should be on increasing value congruence, agility and transformational leadership.

The result that Agile methods can indeed work for large projects is a surprising outcome, since Agile puts so much emphasis on small teams and short sprints. Our results do not imply that project success (or failure) cannot be influenced by project size, but rather we found that project size is not an explaining factor here. Indeed, larger projects seem to fail more often than small projects, but this cannot be necessarily explained by project size. According to our study, project success (or failure) is explained by social factors. This suggests that Agile methodologies could be successfully applied in larger projects, as long as there is high value congruence, agility and transformational leadership. More research is needed to verify and analyse our findings. Future research should be conducted on a larger scale, over longer period of time in order to validate the model.

\section{Acknowledgment}

The authors thank Martijn Goudbeek (Tilburg University) for assistance with the statistical analysis.

\section{References}

[1] L. Cao, K. Mohan, P. Xu, and B. Ramesh, "How extreme does extreme programming have to be? Adapting xp practices to large-scale projects", in System Sciences,
2004. Proceedings of the $37^{\text {th }}$ Annual Hawaii International Conference on. IEEE, 2004, pp. 10-pp.

[2] K.Beck, Extreme programming explained: embrace change. Addison Wesley Professional, 2000.

[3] D.J. Reifer, F. Mauer, and H. Erdogmus, "Scaling agile methods," software, IEEE, vol. 20, no. 4, pp. 12-14, 2003.

[4] B. Boehm, "Get ready for agile methods, with care," Computer, vol. 35, no. 1, pp. 64-69, 2002.

[5] J. Eckstein, Agile software development in the large: Diving into the deep. Addison-Wesley, 2013.

[6] M. Bloch, S. Blumberg, and J. Laartz, "Delivering largescale IT projects on time, on budget, and on value," Harvard Business Review, 2011.

[7] K.A. Jehn, "A multimethod examination of the benefits and detriments of intragroup conflict. Administrative Science Quarterly, vol. 40, no. 2, pp. 256-83, 1995.

[8] J.R. Hackman, The design of work teams. In J. Lorsch (eds.), Prentice Hall, 1987.

[9] B.M. Bass, Leadership and performance beyond expectations, Free Press, 1985.

[10] J.R. Turner, and R. Müller, "Communication and cooperation on projects between the project owner as principal and the project manager as agent," European Management Journal, vol. 22, no. 3, pp. 327-336, 2004.

[11] S. Nerur, R. Mahapatra, and G. Mangalaraj, "Challenges of migrating to agile methodologies, Communications of the ACM, vol. 48, no. 5, pp. 72-78, 2005.

[12] J.R. Hackman, Groups that work (and those that don't), Jossey-Bass, 1990.

[13] K.A. Jehn, G.B. Northcraft, and M.A. Neale, "Why differences make a difference: A field study of diversity, conflict and performance in workgroups, Administrative science quarterly, vol. 44, no. 4, pp. 741-763, 1999.

[14] R.M. Baron and D.A. Kenny, "The moderator-mediator variable distinction in social psychological research: Conceptual, strategic and statistical considerations," Journal of Personality and Social Pshycology, vol. 51, pp. 1173-1182, 1986. 